Meta

Journal des traducteurs

Translators' Journal

\title{
Simultaneous Listening and Speaking in English into Korean Simultaneous Interpretation
}

\section{Tae-Hyung Lee}

Volume 44, numéro 4, décembre 1999

URI : https://id.erudit.org/iderudit/003444ar

DOI : https://doi.org/10.7202/003444ar

Aller au sommaire du numéro

Éditeur(s)

Les Presses de l'Université de Montréal

ISSN

0026-0452 (imprimé)

1492-1421 (numérique)

Découvrir la revue

Citer cet article

Lee, T.-H. (1999). Simultaneous Listening and Speaking in English into Korean Simultaneous Interpretation. Meta, 44(4), 560-572.

https://doi.org/10.7202/003444ar

\section{Résumé de l'article}

L'une des plus grandes particularités de l'interprétation simultanée est qu'il se produitsimultanément l'écoute de la langue source par l'interprète et son interprétation en langue cible. Pour mettre au point cette particularité, nous avons enregistré trente exemples d'interprétation simultanée de l'anglais au coréen et les avons analysés. Nous avons appris par cette analyse que les interprètes simultanés de l'anglais au coréen retiennent $61 \%$ des mots de la langue source et $40 \%$ du temps total de la séance. Et aussi qu'ils montrent plus de précision au moment où ils ne font que l'écoute, par rapport au moment où ils font l'écoute et l'interprétation à la fois. Si la proportion de discours du conférencier est plus élevée avec moins de pause, la précision de l'interprétation est plus faible. En général, il existe une corrélation négative entre le ratio du temps de simultanéité et la précision de l'interprétation simultanée de l'anglais au coréen. Pourtant, quand la langue source a été interprétée par deux interprètes, l'interprétation de celui qui a augmenté le temps de simultanéité avec une proportion plus élevé de discours était plus précise.
Ce document est protégé par la loi sur le droit d'auteur. L'utilisation des services d’Érudit (y compris la reproduction) est assujettie à sa politique d'utilisation que vous pouvez consulter en ligne.

https://apropos.erudit.org/fr/usagers/politique-dutilisation/ 


\title{
Simultaneous Listening and Speaking in English into Korean Simultaneous Interpretation
}

\author{
TAE-HYUNG LEE \\ Hanyang University, Ansan, Korea
}

\begin{abstract}
RÉSUMÉ
L'une des plus grandes particularités de l'interprétation simultanée est qu'il se produit simultanément l'écoute de la langue source par l'interprète et son interprétation en langue cible. Pour mettre au point cette particularité, nous avons enregistré trente exemples d'interprétation simultanée de l'anglais au coréen et les avons analysés. Nous avons appris par cette analyse que les interprètes simultanés de l'anglais au coréen retiennent $61 \%$ des mots de la langue source et $40 \%$ du temps total de la séance. Et aussi qu'ils montrent plus de précision au moment où ils ne font que l'écoute, par rapport au moment où ils font l'écoute et l'interprétation à la fois. Si la proportion de discours du conférencier est plus élevée avec moins de pause, la précision de l'interprétation est plus faible. En général, il existe une corrélation négative entre le ratio du temps de simultanéité et la précision de l'interprétation simultanée de l'anglais au coréen. Pourtant, quand la langue source a été interprétée par deux interprètes, l'interprétation de celui qui a augmenté le temps de simultanéité avec une proportion plus élevé de discours était plus précise.
\end{abstract}

\begin{abstract}
One of the most outstanding characteristics of simultaneous interpretation, an example of complex human information processing, is the continuing overlapping of source language comprehension and target language production. Some 30 real-life English into Korean simultaneous interpretation audio tapes were analyzed to examine this unique feature. The results show that interpreters both listened and spoke for $61 \%$ of the total words uttered by speakers and $40 \%$ of total utterance time. The accuracy of the listening and speaking portion was found to be statistically poorer than that of the listening only portion. When the speaker's speech proportion increased, accuracy decreased due to reduced speaker pauses within the interpreter's speaking portion. As a whole, time simultaneity ratio and accuracy showed a negative correlation. However, the interpreter who increased speech proportion coupled with time simultaneity ratio showed better accuracy than the other when two interpreters worked on the same speech.
\end{abstract}

\section{INTRODUCTION}

Concurrent listening to source language (SL) and speaking of target language (TL) by interpreters engaging in simultaneous interpretation (SI) constitute one of the most complex cognitive processes a human being can exhibit. As was pointed out by Moser (1997), this is an important challenge for researchers in this field, since an in-depth study of this unique phenomenon will reveal some of the secrets of SI.

The particular importance of this is that these phenomena are observable to outside researchers and can be easily quantified for study purposes. Of course, the fact that listening and speaking processes are observable does not necessarily mean that these two processes are the only ones taking place simultaneously in SI. No one 
knows exactly what is going on in the interpreter's cognitive process during SI, and it would be erroneous to assume that no information processing is occurring even during the very short moments when both interpreter and speaker remain silent. Rather, it would be reasonable to imagine that some processes that cannot be externally observed are underway. These unobservable cognitive processes might include conversion from SL to TL, storing, note-taking (Gile 1997), receiving signals through visual channels (Bühler 1985) and reading a terminology list or the interpreter's own notes, among other things.

One could argue that multi-processing is not a rare phenomenon and that it also happens in daily life. During everyday small talk, of course, people anticipate what others will say next and form their own answer in advance. People can also read newspapers while talking on the phone. But speaking and listening at the same time is very rare in daily life (Gerver 1976). Nor can the depth of the concurrent cognitive processing involved in SI be compared to that in daily life, since time constraints and the magnitude of the task are totally different. Besides, concurrent jobs found in everyday life also exhibit their own limits. For example, the high traffic accident rate of drivers using cellular phones while driving clearly demonstrates that cognitive limit exists in one's processing capacity.

Since Korean is not an international language, Korean natives interpret both L2 (English) into L1 (Korean), and L1 into L2. In the former case, understanding English is key for quality SI since comprehension of source language is the most important stage in SI from L2 into L1 (Weller 1991). Korean interpreters' capacity for listening must be limited due to reduced memory capacity for L2 compared to L1, weaker vocabulary and rules stored in long term memory.

In most cases, the performance of English and Korean SI is judged by the quality of the Korean output since English into Korean SI takes up the most time. Therefore, choosing elegant Korean equivalents rather than just conveying the meaning in the TL is very important. Thus, the following argument for interpreting from L2 into L1 quoted in Weller (1991) does not always apply to English into Korean SI .

The basic argument in favor of working only into one's native language is that the interpreter spends little time on the production phase of interpretation since he is more fluent in the native tongue and instinctively selects the correct word choice, grammatical construction and pronunciation. (Weller 1991: 391)

The problem here is that "concrete words are translated more quickly (and more accurately) than abstract words, and high-frequency words are translated more quickly (and more accurately)" (de Groot 1997). Except for the time factor, retrieval of elegant Korean equivalents from long-term memory consumes some part of the cognitive capacity of the interpreter.

Another difficulty arises from syntactic difference, as is the case with English into Japanese SI (Gile 1991). What Gile asserted can be applied to English into Korean SI since Korean interpreters have to hold the English verb for some time so as to put it into the Korean syntax, spending a considerable amount of memory capacity.

This study examines the following questions:

1. Will the quality of the concurrent listening and speaking portion by the interpreter in SI be poorer than that of the listening only portion? 
2. Does the proportion of concurrent listening and speaking by the interpreter affect the total quality of the interpretation in any way?

3. Do the features of SL affect the duration of concurrent listening and speaking by the interpreter?

4. Do interpreters utilize the pause in SL left by the speaker for their SI in order to decrease the proportion of concurrent listening and speaking?

Concerning concurrent listening and speaking time, Chernov (1979) reports an average of $70.5 \%$ of total speaking time in the SL for the English-Russian combination, with a maximum of $89 \%$. Gerver $(1974 \mathrm{~b})$ found that some interpreters could listen and speak simultaneously for over $75 \%$ of the total input-output time, and were still able to interpret correctly over $85 \%$ of the input texts. Gerver (1975) obtained results of $65 \%$ of the total time for interpreters working from French to English.

None of these studies, however, compare the accuracy of concurrent listening and speaking portions with listening only portions.

\section{MATERIALS AND PROCEDURES}

Thirty actual English into Korean SI audio tapes were chosen to obtain statistically meaningful results. As Gile (1994) pointed out, generalizations will be premature if the study is limited to very small samples of subjects. Among the 30 samples, 18 were paired SI, that is, nine SL were each interpreted by two different interpreters. Those were intentionally included to observe the performance of interpreters under the same SL conditions. The material included a US presidential debate, US President Clinton's inauguration ceremony, live coverage of the Gulf War and speeches from international conferences. ${ }^{1}$ The use of "real-life" materials is also important in view of the assertion by Gile's (1994) emphasis on "using experimental materials and conditions as close as possible to field conditions."

Eleven professional conference interpreters were involved in the study. Their mother tongue was Korean and English was their strongest passive language. All of them had at least three years of experience. This eliminated the danger of using student interpreters, as Gile (1995) warned "there may be very significant differences in the way professionals, on the one hand, and students or amateur translators/ interpreters, on the other, perform I/T tasks."

The original English and Korean interpretations were transcribed, and the audio signals were saved for analysis by a personal computer which could measure as small a time segment as 1 millisecond.

Two simultaneity ratios were set up: 1 ) a syllable simultaneity ratio (SSR) and, 2) a time simultaneity ratio (TSR). The SSR, the portion of syllables interpreters both listened and spoke concurrently, was measured by counting the number of syllables in the English text with SI on the computer playing it. The TSR was calculated using the following formula:

TSR $=$ TST - LTI - SPIST $/$ TST

( TST $=$ total speaking time, $\mathrm{LTI}=$ listening time by interpreter, SPIST $=$ speakers' pause within interpreter's speaking time, TST $=$ total speaking time). 
Two different evaluation methods were used for quality assessment. For the quality of a sample as a whole, the number of meaning units in the original English speech was calculated and then it was matched against the Korean interpretation version. For example, when there were 10 meaning units in the SL sample and 5 were interpreted into the TL, the sample was judged as $50 \%$ accurate. For the quality of time simultaneity portion and listening portion, an evaluation based on the number of words, not on the meaning unit, was employed. When all the original English words in the listening portion of an English speech were interpreted into the Korean version, the portion was judged as $100 \%$ accurate, whereas $50 \%$ accuracy was assigned when half of the words in the SL appeared in the TL. This method of evaluation for the simultaneity portion and the listening portion was necessary since the boundary between these portion was not located between sentences all of the time; rather, it was in the middle of sentences most of the time. Some articles or possessive adjectives that are not necessarily interpreted in Korean were not considered in the evaluation. During the quality assessment, importance was given to maintaining consistency of the criteria so as to compare the quality of each sample and portion.

\section{RESULTS}

Speakers exhibited $77 \%$ of speech proportion (SP) while interpreters showed $58 \%$ and the SP of interpreter to speaker (I/S) was 0.76. A negative correlation was found between the speaker's SP (SSP) and accuracy as a whole $(r=-0.47 \mathrm{p}<0.01)$. Interpreter's SP (ISP) demonstrated no change with an increase of the SSP and speaker's syllable per minute (SSPM). Speech rate, or syllables per minute, of a speaker was $231 \mathrm{spm}$, while that of interpreter was $243 \mathrm{spm}$, and the I/S ratio was 1.08. The articulation rate of the speaker was $302 \mathrm{spm}$ while that of interpreter was $400 \mathrm{spm}$, and the I/S was 1.36. Regarding the number of syllables uttered by speakers and interpreters, the I/S ratio was 1.09, which means that interpreters uttered $109 \%$ more syllables than speakers.

Interpreters both listened and spoke concurrently for $61 \%$ of total syllables uttered by the speaker. The syllable simultaneity ratio (SSR) was not influenced by increasing SSP and SSPM. The SSR, however, showed positive correlations with ISP $(r=0.85 \mathrm{p}<0.001)$, interpreter syllables per minute $($ ISPM $)(r=0.52 \mathrm{p}<0.01)$, SPM I/S ratio $(\mathrm{r}=0.33, \mathrm{p}<0.05)$, SP I/S $(\mathrm{r}=0.56, \mathrm{p}<0.001)$, and time simultaneity ratio (TSR) $(\mathrm{r}=0.73, \mathrm{p}<0.001)$.

Interpreters listened and spoke concurrently for $40 \%$ of the total utterance time. This $40 \%$ of the TSR remained unchanged with the increase of speakers' speech rate and articulation rate. The TSR, however, showed a positive correlation with SSP $(\mathrm{r}=0.53, \mathrm{p}<0.01)$, ISP $(\mathrm{r}=0.79, \mathrm{p}<0.001)$, interpreter's speech rate $(\mathrm{r}=0.58, \mathrm{p}<$ $0.001)$, SPM I/S ratio $(\mathrm{r}=0.41, \mathrm{p}<0.05)$ and SSR $(\mathrm{r}=0.73, \mathrm{p}<0.001)$. A negative correlation was obtained between the TSR and accuracy as a whole $(\mathrm{r}=-0.32, \mathrm{p}<$ 0.05).

A t-test showed that the accuracy of the time simultaneity portion was lower than the accuracy of the listening portion $(\mathrm{df}=29, \mathrm{t}=8.81, \mathrm{p}<0.001)$. The accuracy of the time simultaneity portion showed a stronger negative correlation with SSP $(\mathrm{r}=-0.57, \mathrm{p}<0.001)$ than the accuracy of the listening portion with SSP $(\mathrm{r}=-0.35$ $\mathrm{p}<0.05)$. Accuracy of the time simultaneity portion showed a stronger positive 
correlation with SP I/S $(\mathrm{r}=0.51, \mathrm{p}<0.001)$ than the accuracy of the listening portion with SP I/S $(r=0.32 \mathrm{p}<0.05)$. A stronger negative correlation was found between the accuracy of time simultaneity portion with SSPM $(r=-0.68, \mathrm{p}<0.001)$ than the accuracy of the listening portion with SSPM $(r=-0.45 \mathrm{p}<0.01)$. The accuracy of the time simultaneity portion showed a higher positive correlation with SSPM I/S $(\mathrm{r}=0.48, \mathrm{p}<0.01)$ than the accuracy of the listening portion with SSP $(\mathrm{r}=0.36 \mathrm{p}<$ $0.05)$. A stronger negative correlation was obtained between the accuracy of the time simultaneity portion with the SSP $(r=-0.57, \mathrm{p}<0.001)$ than the accuracy of the listening portion with SSP $(\mathrm{r}=-0.35 \mathrm{p}<0.05)$.

\section{DISCUSSION}

\subsection{SL and TL Factors}

The greater SSP over ISP contradicts Barik's assertion (1973) that "T generally engaged in speaking for a greater proportion of the time than S." But it is in line with Lee (1999) who found sentence SP for interpreters was 79.6\%, while that for speakers was $86.2 \%$ for English into Korean SI. This might be attributable to the unique feature of SI in general. It would be reasonable to assume that interpreters engaging in SI require more processing capacity than speakers.

The fact that ISP is not influenced by SSP indicates the interpreter's processing capacity is already at its limit in keeping up with SL which is faster than the optimal speed of 100-120 wpm (Seleskovitch 1978), or 100wpm (Barik 1975). In this situation, the interpreter cannot increase ISP beyond 58\% since a minimum capacity should be reserved for other processing involved in SI. The ISP at 58\% means that interpreters fill $42 \%$ of total speaking time with silence. Although the audience listening to the SI assumes such silence reflects a loss of information (Dejean Le Féal 1990), interpreters have no other choice in this situation.

The greater I/S articulation rate of 1.36 compared to SSPM I/S of 1.08 suggests that interpreters speak quickly so as to cram their output once they have a chance to speak. Although interpreters utter more words in their SI than the original speech, the quality of the SI is far from being $100 \%$. It becomes clear that, for an omissionfree interpretation, more Korean words in TL are necessary.

\subsection{Syllable simultaneity ratio}

SSR in this study is similar to the TSR in other related findings. The SSR is also about equal to ISP. The unchanged SSR with increasing SSP and SSPM should be understood to mean that the interpreters' capacity is already at maximum level and cannot increase SSR further. The positive correlation between SSR and SP I/S as well as SPM I/S means the overlapping syllable portion increases as the interpreter increases SP.

\subsection{Accuracy of time simultaneity portion}

Theoretically, interpreters should be able to speak with pauses only for breathing during SI. But it was not the case in SI since TSR remained at only $40 \%$. This clearly shows that very complex information processing is going on in the interpreters' 
cognitive system. We cannot attribute this low TSR to a lack of capacity on the part of interpreters, since they are top ranking interpreters with good reputations. In optimal condition samples, they recorded very high accuracy. Therefore, the reason for the low TSR seems to be the unique situation of English into Korean SI.

The TSR increases as interpreters and speakers accelerate their utterances. One noteworthy observation is that TSR was free from the change in SSPM or speakers' articulation rate. In other words, TSR was influenced by the SP factor rather than by speed of SL.

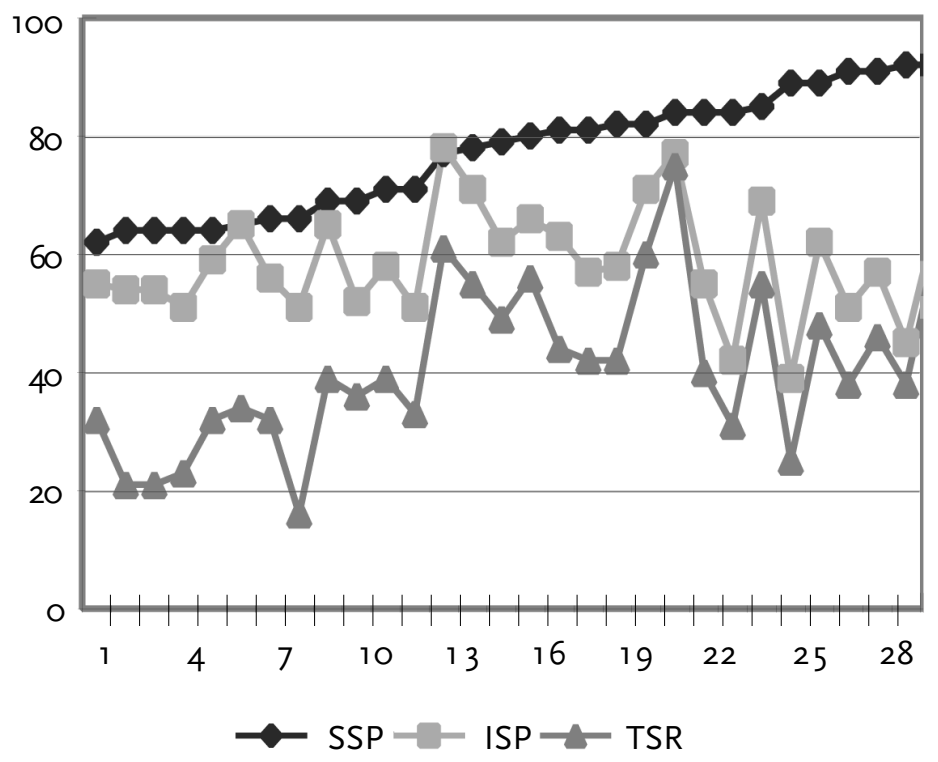

Figure 1

SSP, ISP and TSR in 30 samples

Figure 1 answers some important questions about the relations between SSP, ISP and TSR. The first is that the speaker's pause within ISP decreases as SSP increases and vice-versa. This is because the gap between ISP and TSR is the speaker's pause within ISP. As the SSP increases, speaker's pause within ISP decreases proportionally, thereby leaving ISP unchanged. This quite reasonable assumption is confirmed by the correlation $(r=0.87, \mathrm{p}<0.001)$ between the changes in speaker's pause in total utterance time and speaker's pause within ISP.

In samples from 1 to 13 in Figure 1, where SSP is low, we can see interpreters keep the TSR as low as 30\% with 50\% of the ISP. In other words, interpreters are able to engage in listening, converting, and other forms of processing with a certain reduction in TL delivery. At the same time, information density is not so high due to the low SSP. This leads to almost 90\% accuracy of the SI samples. On the other hand, in samples from 17 to 30 the situation is totally different. The reduced speaker's pause resulting from high SSP, which is the real space for multi-processing, makes the TSR high, and interpreters do not have the luxury of listening to the SL without uttering their TL. This means that interpreters in these samples experience their listening 
overlapped by TL production most of the time. Compounding the problem even further, the high SSP is accompanied by high information density, which in turn makes interpreters' processing more difficult as proven by the negative correlation between SSP and accuracy $(r=-0.47 \mathrm{p}<0.01)$. Concerning the density of speech, Gile (1997) explains:

High speech density may be the most frequent source of interpretation problems and failures. It is associated with fast delivery of the speech. (Gile 1997: 205)

Barik (1975) also said "the more the S speaks in a fixed period of time, the more often and the greater the amount of material likely to be omitted by the T."

Therefore, this increased TSR and high density resulting from high SSP really constitute a vulnerable spot in the SI (de Groot 1997). This TSR neatly illustrates the "excessive multi-processing" in Lee (1999) when he explains the drop in accuracy of SI due to high SSP.

But it is too early to conclude that accuracy of SI decreases when interpreters increase TSR, because of the following counter-example: A paired t-test for 18 samples that we included intentionally, that is, 9 pairs of interpretations for 9 speeches, revealed that the SI with higher TSR record better quality than others with relatively low TSR $(\mathrm{df}=8, \mathrm{t}=3.18, \mathrm{p}<0.05)$. This means that, under the same SSP conditions, higher TSR brings better SI quality than lower TSR. This might not seem to be in line with the above findings.

A close look at the trend, however, reveals that although the quality of one interpretation with higher TSR is slightly superior to the other, neither interpreter could completely escape the negative correlation between accuracy and TSR. In other words, the difference between the two interpretation qualities was not big enough to reverse the negative correlation between TSR and accuracy as a whole.

To summarize the present section up to this point, speeches with high TSR have high SSP and highly dense information; for these speeches, interpreters engaging in English into Korean SI have no choice but to accelerate their ISP as well as TSR. These speeches are intrinsically difficult and quality will be lower than speeches with low SSP in the long run. Even in this adverse situation, if an interpreter can increase his SSP and TSR relative to the other interpreter working on the same speech, it is reasonable to assume that the interpreter showing high TSR is carrying out more efficient processing than the other interpreter with low ISP and TSR.

\subsection{Accuracy of time simultaneity portion and listening portion}

The result that the accuracy of the listening and speaking portion are much lower than that of the listening portion is in line with Gerver (1976): "significantly more was correctly interpreted in the pause than no-pause condition." The low accuracy of the time simultaneity portion also explains the above result of poor quality of samples with high TSR, in that the quality of SI will be sacrificed when the poor quality portion, that is, the listening and speaking portion, occupies a greater part in the total SI.

It is quite obvious that interpreters, when interpreting simultaneously, may not "listen" in the same way as they listen in silence without uttering the TL. Therefore, interpreters with the capacity of processing speeches faster than $200 \mathrm{wpm}$ cannot 
exhibit the same capacity in SI because they have to distribute their capacity among several tasks, as they do during the time simultaneity portion. Moreover, the average speed of these samples was around $150 \mathrm{wpm}$, which is much faster than the optimal speed for SI. As Goldman-Eisler (1972) said, "comprehension requires the most attention" and this comprehension is the first phase for SI. During the time simultaneity portion, however, comprehension of SL suffers. According to Gerver (1974b), "simultaneous listening and speaking can impair recall of the material listened to while speaking." Poor understanding directly obstructs the subsequent processing involved in converting and delivering in the TL. This result clearly indicates that during the time simultaneity portion there is a limit to the processing capacity of interpreters. According to Weber (1990: 45),

Listeners normally have a natural "absorption threshold" beyond which they can no longer absorb and process information. This threshold may be higher if they are listening to their native language and lower when listening to a foreign language.

The gap between the accuracy of the time simultaneity portion and the accuracy of listening portion becomes greater as the SSP increases. This is proved by the negative correlations between SSP and the accuracy of the time simultaneity portion $(r=-0.57$, $\mathrm{p}<0.001$ ), while the correlation between SSP and the accuracy of the listening portion is $(\mathrm{r}=-0.35, \mathrm{p}<0.05)$. The gap becomes smaller when the interpreter increases ISP I/S and SSPM I/S. The smaller the gap, the more accurate the SI as a whole. Therefore, improving the accuracy of the time simultaneity portion is a key for quality SI. This clearly demonstrates that one should allocate processing capacity evenly between multi-modules in SI to obtain quality interpretation results.

\subsection{Reasons for low accuracy of the time simultaneity portion}

As Gile (1997) points out, the time simultaneity portion seems to constitute "an intrinsic difficulty in interpreting that cannot be explained by interpreter's weakness." The reasons for the poor quality of the time simultaneity portion might include the following:

The first may be, as repeatedly mentioned, excessive multi-processing during the time simultaneity portion. Although no one can describe the process in the interpreter's cognitive system exactly, it is clear that uttering TL is added to the ongoing process when interpreters speak and listen simultaneously. This added "novel stimuli" clearly needs "conscious processing", as Velmans (1991) states. This additional processing clearly overloads the cognitive processing of the interpreter. According to Gile (1995: 161),

Interpretation requires some sort of mental "energy" that is only available in limited supply. Interpretation takes up almost all of this mental energy, and sometimes requires more than is available, at which times performance deteriorates.

This is also why the quality of the time simultaneity portion is more easily influenced by SL factors than the listening portion.

The second reason may be the involvement of the interpreter's own voice with SL input. Two audio signals are being input to the interpreter's ear and interfere with the listening process of the interpreter. According to Isham (1994: 208), 
In sum, recall in spoken language interpreters is poorer in the final clause, which may be an effect caused by the interference with a phonological memory of receiving two streams of speech simultaneously.

Therefore, the situation becomes more difficult for interpreters than just listening without speaking. Gerver's study (1976) on the adverse effect of noise on the quality in SI is relevant in this context. Darò (1994) adds that "this phonological interference disrupts working memory." In addition to all this acoustic interference, interpreters must also allocate a certain amount of attention to monitoring their own utterances: maintaining their voice at an optimal level and correcting any error in TL. Interpreters, as a way of mitigating this problem, turn up the volume of SL or lower the volume of their own voice.

The third reason is the conversion from the SL to the TL, as explained by Frauenfelder (1997): "conversion from listening to speaking also involves translation from one language to another." Conveying the meaning of SL into TL at a deep structure level is not an easy job and surely expends some capacity. This does not exhaust the list of multi-processing possibilities in the time simultaneity portion since other processing such as reading a pre-prepared terminology list and looking at the speaker may be involved. Furthermore, anticipation will not function as well as it does in the listening only condition.

For these reasons, many studies report the high processing load of SI and inherent limitations of the interpreter (Massaro 1997). Lambert (1988) reports significantly higher recall after listening alone than simultaneous interpretation or shadowing. Darò (1994) and Isham (1994) also reported poorer recall after SI. Hyona (1995) reports that, in a pupil dilation experimental study, processing load in SI is greater than in listening.

\subsection{Pauses in SI}

A comparison of TSR at $40 \%$ and ISP at 58\% reveals some important facts. Considering the formula for TSR, the speaker pauses within ISP are responsible for the decrease from $58 \%$ to $40 \%$. In other words, the difference of $18 \%$ is the sum of speaker pauses included within the interpreter's speaking portion of $58 \%$. So, speaker pause at $18 \%$ out of total pause at $23 \%(100 \%$ - SSP $77 \%)$ seems to be clustered within the interpreter's speaking portion. This, in turn means that the listening only portion contains only $5 \%$ out of $23 \%$.

This uneven distribution of speaker pause can also be confirmed in another way. If speaker pauses are distributed proportionally, some $58 \%$ of them must be in the interpreter's speaking portion, while $42 \%$ must be in the listening portion, as ISP is $58 \%$. So, according to a calculation of this type, the $23 \%$ speaker pause should be allocated so that $13.3 \%$ is in interpreter's speaking portion and $9.7 \%$ in the listening portion. A detailed calculation of speakers' pauses in 30 samples reveals that, again, about $18 \%$ of the pauses are in the interpreter's speaking portion, while some $5 \%$ are in the listening portion.

These two verification methods show that more speaker pause time is located in the interpreter's speaking portion than listening portion. These results seem to support the finding that interpreters utilize the pause in the SL. But it would not be 
correct to say that interpreters hold their TL production until they meet the speaker's pauses in SL. If this were true, interpreters would have to keep the converted message in their memory while waiting for pauses established by the speaker. This kind of waiting and holding of memory would consume some processing capacity and the un-refreshed memory would not be able to accommodate further input.

Rather, it would be more reasonable to describe the situation as the interpreters reducing their TL production under the overloaded processing of listening and speaking during a speech with little pause time, and paying more attention to SL comprehension. This is frequently witnessed in SI when interpreters stop delivering in the TL and pay all available attention to the listening task if the particular SL portion is exceptionally complicated. Let alone the question of whether the pause durations are long enough to be used by interpreters, this seems to suggest the existence of a tendency for interpreters to reduce the difficult processing of overlapping of SL comprehension and TL production in their interpretation.

\subsection{SI and translation}

Among the 30 samples, published written translations in Korean for seven samples of the US presidential debate, were available to compare the number of words with SL. It was found that interpreters used $95 \%$ of SL syllables, while translations contained $155 \%$ of the SL syllables. This means that, for an omission-free SI, interpreters should utter at least $155 \%$ more syllables than the SL version. ${ }^{2}$ As speakers in these seven samples spoke at a rate of $196 \mathrm{wpm}$ (294 syllable), interpreters should utter 456 syllable per minute to make their SI as accurate as the written translation. It is clear that this is impossible for interpreters to accomplish when we consider the speed of 330 syllable to 350 syllables per minute of Korean telecasters on TV who just read a written text (KBS 1991). Therefore, physically, a certain amount of omission in English into Korean SI in this situation seems inevitable regardless of the interpreter's capacity.

Besides the speed of SL, expressions in SL were very formal and elegant in the case of the presidential debate. In interpreting these SL, interpreters could not use simple and easily retrieved expressions in the TL because the dignity of TL would suffer. So, choice of elegant style at the expense of cognitive capacity is a must for Korean interpreters. This is the dilemma mentioned by Gile (1995: 171).

For instance, the interpreter may try too hard to produce an elegant reformulation of segment $\mathrm{A}$, and therefore not have enough capacity left to complete a listening task on an incoming segment B. Had he or she been content with a simpler reformulation, enough capacity would have been left over for the L (listening and analysis) effort.

\section{CONCLUSION}

The accuracy of the time simultaneity portion was found to be poorer than the accuracy of the listening portion mainly due to the multi-processing involved in the time simultaneity portion. The SSR of $61 \%$ showed a positive correlation with ISP and interpreter factors. The TSR and accuracy of a SI had a negative correlation. However, the interpreter who maintains higher TSR showed better quality when two interpreters worked on the same SL. The clustered speaker's pause in an interpreter's 
speaking portion demonstrates that interpreters tend to make an effort to reduce the difficult task of listening and speaking simultaneously.

By applying these findings to interpreter training, we can consider reducing the TSR and SSR. This is, however, unacceptable because it is not in line with the nature of SI and will leave long unfilled pauses in SI.

Therefore, better advice to interpreters would be to increase ISP and TSR as much as possible to improve the quality of the SI. Considering that SI is, by its very nature, an attention sharing system (Gerver 1975, Weller 1991), two important suggestions can be proposed for interpreter training. The first is making the allocation of processing capacity to each phase of the SI in an automatic manner, not an effortful processing (Shreve 1997). The importance of this automatic task was closely studied by Darò (1994). Automatic allocation will increase the effectiveness of allocation and the saved capacity can be available for faltering processing. Second is increasing the sum of total cognitive processing capacity for SI. These are necessary to improve the quality of SI by not allowing the quality of the time simultaneity portion to fall abruptly.

It would be advisable to train interpreters to listen to SL with a minimal amount of capacity. Imposing extra attention-consuming exercises during the listening can be one way. This will enable interpreters to cope with speech with high SSP during actual listening and speaking situations. For memory effort, a unique language specific strategy should be explored to lessen the load on memory in handling Korean. This will prevent the loss of information in memory for prolonged time. In the case of retrieving Korean equivalents, reducing the capacity and time for retrieval is important. To be more specific, sight translation using elegant English text can be a good choice. ${ }^{3}$ This quick retrieval of Korean expression with minimum attention will prevent the loss of well understood and converted messages at the final stage. Through this training, interpreters can save considerable amounts of attention which can be allocated to understanding phases or to anticipation. Then they will have a concrete understanding of SL and come up with omission-free TL production.

Needless to say, knowing the subject thoroughly is a key to quality interpretation. In view of the simultaneity situation in SI, this prior knowledge will improve the accuracy of listening and speaking portions by assisting SL understanding in overloaded situations. If interpreters master this strategy, they will be able to have "a more comprehensive, macroview of the evolving message" (Moser 1997).

\section{NOTES}

* Support for this research was provided by a grant from Sangji Junior College in 1997.

1. Live coverage of the Gulf war through SI in 1991 was an epoch-making event in Korea. After the war, SI became widely known to laymen in Korea.

2. The number of words in SI will be even greater when we consider the roundabout quality of spoken language in contrast with the more condensed expression in written translation.

3. Sight translation is an important training course for would-be interpreters, who are supposed to orally translate an SL text while reading it.

\section{REFERENCES}

BARIK, H. C. (1973): “Simultaneous Interpretation: Temporal and Quantitative Data”, Language and Speech, 16-3, pp. 237-270. 
- (1975): “Simultaneous Interpretation: Qualitative and Linguistic Data", Language and speech, 18-3, pp. 272-297.

BüHLER, H. (1985): “Conference Interpreting, a Multichannel Communication Phenomenon”, META, 30-1, pp. 49-54

Chernov, G. (1979): "Semantic Aspects of Psycholinguistic Research in Simultaneous Interpretation", Language and Speech, 22-3, pp. 277-295.

- (1994): "Message Redundancy and Message Anticipation in Simultaneous Interpretation," in S. Lambert and B. Moser-Mercer (Eds.), Bridging the gap: Empirical Research in Simultaneous Interpretation.(pp. 139-154). Amsterdam: John Benjamins Publishing Co.

Darò, V. and F. Fabbro (1994): "Verbal Memory During Simultaneous Interpretation: Effects of Phonological Interference," Applied Linguistics. 15-4, pp. 365-381.

Dejean Le Feal, K. (1990): "Some Thoughts on the Evaluation of Simultaneous Interpretation", in D. M. Bowen (Eds.), Interpreting-Yesterday, Today, and Tomorrow: American Translators Association Scholarly Monograph Series Vol. IV. (pp. 154-160). New York: State University of New York at Binghamton.

Frauenfelder, U.H. and H. Schriefers (1997): "A Psycholinguistic Perspective on Simultaneous Interpretation," Interpreting, 1/2, pp. 55-90.

Gerver, D. (1974a): "The Effects of Noise on the Performance of Simultaneous Interpreters: Accuracy of Performance", Acta Psychologica, 38-3, pp. 159-167

- (1974b): "Simultaneous Listening and Speaking and Retention of Prose", Quarterly Journal of Experimental Psychology, 26, pp.337-341.

— (1975): “A Psychological Approach to Simultaneous Interpretation", META, 20-2, pp. 119128.

- (1976): "Empirical Studies of Simultaneous Interpretation: A Review and a Model", in R.W. Brislin (Ed.), Translation, Applications and Research (pp.165-207), New York, Gardner Press.

GiLe, D. (1991): “The processing capacity issue in conference interpretation”, Babel, 37, pp.15-27.

- (1994): "Methodological Aspects of Interpretation and Translation Research", in S. LAMBERT and B. Moser-Mercer (Eds.), Bridging the gap: Empirical Research in Simultaneous Interpretation (pp. 39-56), Amsterdam, John Benjamins Publishing Co.

- (1995): Basic Concepts and Models for Interpreter and Translator Training, Amsterdam, John Benjamins Publishing Co.

- (1997): "Conference Interpreting as a Cognitive Management Problem," in J. H. Danks, G. M. Shreve, G. M Fountain and M. K. McBeath (Eds.), Cognitive Processes in Translation and Interpreting (pp. 196-214), London, Sage Publications.

Goldman-EISLer (1972): "Segmentation of Input in Simultaneous Translation", Journal of Psycholinguistic Research, 1-2, pp. 127-140.

de Groot, A. M. B. (1997): “The Cognitive Study of Translation and Interpretation," in J. H. Danks, G. M. Shreve, G. M Fountain and M. K. McBeath (Eds.), Cognitive Processes in Translation and Interpreting (pp. 196-214), London, Sage Publications.

HyonA, J., J. Tommola and A. Alaja (1995): "Pupil Dilation as a Measure of Processing Load in Simultaneous Interpretation and Other Language Tasks," Quarterly Journal of Experimental Psychology, 48A-3, pp. 598-612.

Isham, W. P. (1994): "Memory for Sentence After Simultaneous Interpretation: Evidence Both for and against Deverbalization," in S. LAMbert and B. Moser-Mercer (Eds.), Bridging the gap: Empirical Research in Simultaneous Interpretation(pp. 191-212). Amsterdam: John Benjamins Publishing Co.

Korean Language Studies Association Of KBS (1991): "The Phonetic Characteristics of Broadcast Language in South and North," The KBS Korean Language Series (in Korean), 30, pp. 61-99.

Kruz, I. (1987): "Conference Interpreting- Myth and Reality," in K. M. Kummer (Ed.), Across the Language Gap: Proceedings of the 28th Annual Conference of the American Translators Association (pp. 315-320), Medford, NJ: Learned Information, Inc. 
Lambert, S. (1988): "Information Processing Among Conference Interpreters: A Test of the Depth-of Processing Hypothesis", META, 33-3, pp. 377-387.

LeE, T. (1999): "Speech Proportion and Accuracy in English into Korean Simultaneous Interpretation", META, 44-2, pp. 260-267.

Moser-Mercer, B. (1997): "Beyond Curiosity: Can Interpreting Research Meet the Challenge?," in J. H. Danks, G. M. Shreve, G. M Fountain and M. K. McBeath (Eds.), Cognitive Processes in Translation and Interpreting (pp. 176-195), London, Sage Publications.

Seleskovitch, D. (1978): Interpreting for International Conferences. Washington D.C., Pen and Booth.

Shreve, G. M. and Diamond, B. J. (1997): "Cognitive Processes in Translation and Interpreting: Critical Issues," in J. H. Danks, G. M. Shreve, G. M Fountain and M. K. McBeath (Eds.), Cognitive Processes in Translation and Interpreting (pp. 233-251), London, Sage Publications.

Velmans, M. (1991): “Is Human Information Processing Conscious?, Behavioral and Brain Sciences, 14, pp. 651-669.

Weber, W. K. (1990): "The Importance of Sight Translation in an Interpreter Training Program," in D. M. Bowen (Eds.), Interpreting-Yesterday, Today, and Tomorrow: American Translators Association Scholarly Monograph Series Vol. IV. (pp. 44-52). New York, State University of New York at Binghamton.

Weller, G. (1991): “The Influence of Comprehension Input on Simultaneous Interpreter's Output," Proceedings of the 12th World Congress of FIT. pp. 391-401. 